\title{
Effect of primary-care spirometry on the diagnosis and management of COPD
}

\author{
P.P. Walker*, P. Mitchell ${ }^{\#}$, F. Diamantea*, C.J. Warburton ${ }^{\#}$ and L. Davies ${ }^{\#}$
}

ABSTRACT: Primary-care spirometry has been promoted as a method of facilitating accurate diagnosis of chronic obstructive pulmonary disease (COPD). The present study examined whether improving rates of diagnosis lead to improvements in pharmacological and nonpharmacological management.

From 1999 to 2003, the current authors provided an open-access spirometry and reversibility service to a local primary-care area, to which 1,508 subjects were referred. A total of $797(53 \%)$ had pre-bronchodilator airflow obstruction (AFO). Of the subjects who underwent reversibility testing, $19.3 \%$ were no longer obstructed post-bronchodilator. The results and records of a subgroup of 235 subjects with post-bronchodilator AFO were examined.

Of the 235 subjects, 130 received a new diagnosis, most commonly COPD. The patients with COPD were significantly undertreated before spirometry and testing led to a significant increase in the use of anticholinergics (37 versus 18\%), long-acting $\beta$-agonists (25 versus $8 \%$ ) and inhaled steroids (71 versus $52 \%$ ). More than three quarters of smokers received smoking cessation advice but very few were referred for pulmonary rehabilitation.

In conclusion, primary-care spirometry not only increases rates of chronic obstructive pulmonary disease diagnosis, but it also leads to improvements in chronic obstructive pulmonary disease treatment. The use of bronchodilator reversibility testing in this setting may be important to avoid misdiagnosis.

KEYWORDS: Bronchodilation, chronic obstructive pulmonary disease, primary care, spirometry

(

$\mathrm{n}$ primary care, patients are commonly misdiagnosed as having asthma when in fact they have chronic obstructive pulmonary disease (COPD). GRIFFITHS et al. [1] showed that more than a third of patients $>50 \mathrm{yrs}$ of age registered as asthmatic actually had COPD. Misdiagnosis potentially results not only in an individual patient being misinformed and incorrectly educated about their condition, but can also lead to incorrect management. The place, timing and rationales for prescribing bronchodilator and anti-inflammatory treatments are clearly different in asthma and COPD and without a certain diagnosis, effective COPD interventions may not be considered. Of particular importance is referral for pulmonary rehabilitation. Although likely to benefit the majority of patients with breathlessness due to lung disease, in the UK this treatment is in practice often limited to individuals with a diagnosis of COPD.

In light of this, the widespread use of spirometry testing to improve the diagnosis of COPD has been promoted [2]. The latest General Medical Services (GMS) contract for primary care in England, Wales and Northern Ireland introduced a number of indicators to enhance COPD diagnosis and management [3]. Primary-care practices receive "points", and ultimately additional payment, for keeping a register of COPD patients (5 points), for using spirometry and reversibility testing to confirm a diagnosis of COPD (16 points), and for recording current smoking status and providing cessation advice to current smokers with COPD (12 points). The exact monetary value of each point varies according to practice size and the proportion of patients in whom the target is achieved, but an average-sized practice achieving the highest target for all measures could have earned $>€ 3,600$ in the financial year 2004-2005.

A number of recent publications have looked at the use of primary-care spirometry and reasons for its underuse, in particular addressing practical problems with delivery and interpretation of results $[4,5]$. The aim of the present study was to investigate whether the use of spirometry in primary care to diagnose COPD resulted in improvements in management. More specifically, the current authors wanted to find out whether both pharmacological and nonpharmacological
AFFILIATIONS

*Division of Infection and Immunity, School of Clinical Sciences,

University of Liverpool.

${ }^{\#}$ Aintree Chest Centre, University

Hospital Aintree, Liverpool, UK.

CORRESPONDENCE

P.P. Walker

Clinical Science Centre

University Hospital Aintree

Lower Lane

Liverpool

L9 7AL

UK

Fax: 441515295886

E-mail: ppwalker@liverpool.ac.uk

Received:

February 082006

Accepted after revision:

July 112006 
treatments would be utilised in a way that is consistent with current management guidelines [6, 7]. An additional aim was to establish the usefulness of both bronchodilator reversibility testing and trials of oral corticosteroids in what is a large, diverse and unselected population.

\section{MATERIALS AND METHODS}

A local primary care trust (Knowsley Primary Care Trust, Merseyside, UK) was keen to try to improve current diagnosis and management of COPD, and in 1998 funded open-access spirometry for all primary-care practices within one district (Kirkby, Metropolitan Borough of Knowsley, UK). There were 11 primary-care groups within the district and a total of 29 fulland part-time primary-care physicians (PCPs), who deliver services to just over 57,000 people. Recommendations were made to PCPs suggesting patients who were appropriate for referral (individuals $>40$ yrs old who were smokers or exsmokers and had respiratory symptoms). Although, at this stage, the service was primarily intended for diagnosis rather than screening, the referral decision was left in the hands of the PCPs and any patient referred was offered an appointment. Patients had to reside within a strictly defined geographical area and referral was made using a standard proforma. The referrer was responsible for ensuring that the subject was medically fit for testing. Patients were asked to omit the use of short-acting bronchodilators for $6 \mathrm{~h}$ and long-acting bronchodilators for $12 \mathrm{~h}$ before spirometry.
A respiratory technical officer with $>25 \mathrm{yrs}^{\prime}$ experience (P. Mitchell) performed spirometry testing at a "health suite" in the local community. At the time of the appointment, a record was made of age, height, smoking history and current medications. A noncomputerised wedge bellows spirometer (Vitalograph, Buckingham, UK) was used, which produced a real-time, volume-time trace. Volume and time calibration was performed daily and comparison against a biological control performed weekly. Subjects performed forced spirometry manoeuvres in accordance with European Respiratory Society guidelines [8] and continued until at least three technically acceptable manoeuvres were performed and two forced vital capacity (FVC) manoeuvres within $150 \mathrm{~mL}$ of each other were obtained. All tests included in the study met these criteria. Forced expiratory volume in one second (FEV1) and FVC were recorded to the nearest $25 \mathrm{~mL}$ and the FEV1/FVC ratio was documented. Predicted values were calculated using those derived from the European Coal and Steel Community population [9].

Bronchodilator reversibility testing was also available. When requested by the $\mathrm{PCP}$, this was performed in subjects with prebronchodilator airflow obstruction (AFO) defined as FEV1/ FVC $<0.7$ and/or FEV $1<80 \%$ predicted. In the test, $5 \mathrm{mg}$ salbutamol and $500 \mu \mathrm{g}$ ipratropium bromide, diluted in $2 \mathrm{~mL}$ $0.9 \%$ saline, were administered through a Porta-neb sidestream nebuliser (RL Dolby \& Co., Stirling, UK) until all the solution was inhaled (usually $\sim 10 \mathrm{~min}$ ). Spirometry was then repeated
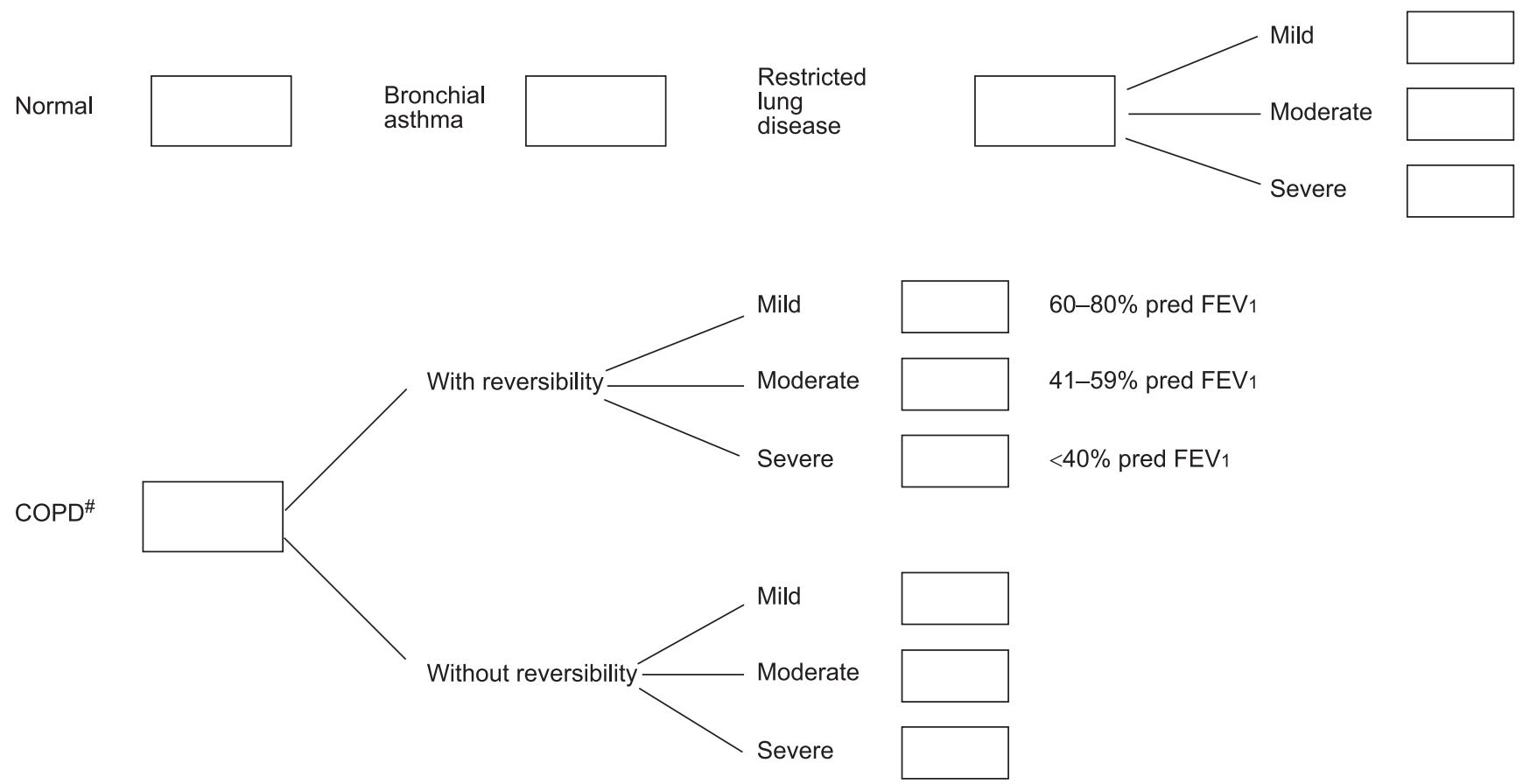

FIGURE 1. Proforma for reporting spirometry results to the referring primary-care physician. COPD: chronic obstructive pulmonary disease; \% pred: percentage of predicted value; FEV1: forced expiratory volume in one second. The notes for results for spirometry were as follows: 1) normal spirometry excludes COPD but not asthma; 2) obstructive spirometry may be due to COPD, asthma and other conditions; 3) restrictive spirometry, if this is moderate or severe and no cause is known then referral for a further opinion from a chest physician is recommended. The notes for results for bronchodilator (BD) reversibility were as follows: 1) large BD reversibility suggests the possibility of underlying asthma. These patients should be treated aggressively with BDs and inhaled steroids; 2) significant BD reversibility can occur in COPD and suggests that the use of inhaled/oral BDs is appropriate. Inhaled steroids should be considered in these patients; 3 ) if there is no significant BD reversibility, a trial of inhaled BDs is still indicated as symptomatic benefit can still occur. ${ }^{*}$ : patients with COPD may be suitable for pulmonary rehabilitation. If this is appropriate, please refer to Dr Lisa Davies at University Hospital Aintree for assessment and onward referral to the rehabilitation programme. 
after $45 \mathrm{~min}$. Reversibility testing was not performed if the patient declared an intolerance to either bronchodilator agent. The PCP was also able to request reversibility assessment to oral corticosteroids. If this was requested, the PCP prescribed $30 \mathrm{mg}$ prednisolone to be taken daily for 14 days and then spirometry was repeated.

During 1998, a consultant respiratory physician reviewed all spirometry data, along with information contained on the referral proforma. The results were reported as obstructive, normal or restrictive and a likely diagnosis of asthma, COPD or "other" was suggested. From the start of 1999, the reporting process was converted into a simple flowchart, which was completed by a senior respiratory technician (fig. 1). Spirometry results were returned to the referring PCP with this report.

Any change to patient management as a result of spirometry was left entirely in the hands of the referring PCP. Specialist help was available if a formal patient referral was made to the local secondary-care service. Secondary-care referral was necessary to access pulmonary rehabilitation.

Details of all spirometry tests performed between 1998 and 2003 were entered onto a database. The 11 referring practices were asked to participate in further analysis of the effect of spirometry testing and all agreed. The local primary-care research group gave ethical approval for the study. The aim was to review the clinical records of more than half of the subjects with post-bronchodilator airflow obstruction. Five out of the 11 practices were selected randomly using a computergenerated random number table, and all patients referred from these practices between 1999 and 2003 who had obstructive pre-bronchodilator spirometry were identified. The start date was set at 1999 to overcome bias related to early dissemination of the availability of the service and to ensure consistent reporting methods. A single researcher (P.P. Walker) reviewed all available primary- and secondary-care notes. Records were made of: diagnosis before spirometry; treatment before spirometry; discussion or referral for smoking cessation support after spirometry; change(s) in pharmacological treatment within 3 months of spirometry (defined as the collection of three consecutive monthly prescriptions); referral for pulmonary rehabilitation or secondary care input within
6 months of spirometry; rate of exacerbations requiring antibiotics and/or steroids in the $2 \mathrm{yrs}$ before and after spirometry; and review or follow-up within hospital at any time.

\section{Analysis}

Group data were analysed using paired and unpaired t-tests where data was normally distributed and Mann-Whitney Utest where it was not. Single variable data were analysed using the Chi-squared test. A p-value $<0.05$ was regarded as significant.

\section{RESULTS}

\section{Demographics}

A total of 1,508 people were referred to the spirometry service between January 1999 and December 2003. Baseline demographics and pre-bronchodilator lung function are shown in table 1. Of these, $797(53 \%)$ subjects had pre-bronchodilator AFO defined as FEV1/FVC $<0.7$. Subjects with AFO were older $(p<0.001)$ and more likely to be current smokers $(\mathrm{p}<0.001)$.

\section{Pattern of referral}

Overall, 1,508 (2.6\%) out of 57,010 patients registered at the 11 practices in the study were referred for and attended spirometry testing. The referral rate varied between practices, with as many as $6.9 \%$ of registered patients referred from one practice and as few as $1 \%$ from another practice. The median referral rate was $1.8 \%$. An inappropriate referral was considered to be any patient $<40 \mathrm{yrs}$ old and/or a lifelong nonsmoker. By these criteria, 411 referrals (28\%) were inappropriate.

\section{Reversibility testing}

A total of 469 out of 797 subjects with pre-bronchodilator AFO underwent reversibility testing. Of these, 393 (80.7\%) subjects had persistent airflow obstruction while 76 (19.3\%) were no longer obstructed. Of these 76 subjects, 45 also had FEV1 $>80 \%$ pred. No subject with a pre-bronchodilator FEV1/FVC ratio $<0.52$ reversed to normal. No side-effects from the bronchodilator agents used for reversibility testing were reported.

A total of 371 subjects, who had already completed bronchodilator reversibility testing, underwent assessment of oral

TABLE 1 Baseline demographics of subjects undergoing spirometry testing between 1998 and 2003

\begin{tabular}{|c|c|c|c|c|}
\hline & Total & Airflow obstruction $^{\#}$ & No airflow obstruction ${ }^{\#}$ & $p$-value \\
\hline Patients n & 1508 & 797 & 711 & \\
\hline Female & $939(60)$ & $450(56)$ & $489(69)$ & NS \\
\hline Current smokers & $756(50)$ & $439(55)$ & $317(45)$ & $<0.001$ \\
\hline Ex-smokers & $501(33)$ & $287(36)$ & $214(30)$ & 0.001 \\
\hline FEV $1 \%$ pred & $76 \pm 25$ & $64 \pm 23$ & $93 \pm 18$ & $<0.001$ \\
\hline
\end{tabular}

Data are presented as mean \pm SD or $n(\%)$, unless otherwise stated. FEV1: forced expiratory volume in one second; FVC: forced vital capacity; \% pred: percentage of predicted value; NS: not significant. ${ }^{*}$ : defined as FEV1/FVC $<0.7$ 
corticosteroid reversibility. Only $15(4 \%)$ subjects had a $>500 \mathrm{~mL}$ improvement in FEV1 after prednisolone; a further $47(13 \%)$ improved their FEV1 by $200-500 \mathrm{~mL}$. Of the 15 subjects who had a $>500 \mathrm{~mL}$ improvement in FEV1 after steroids, 11 also had a $>500 \mathrm{ml} \mathrm{FEV1} \mathrm{improvement} \mathrm{after}$ bronchodilators. In the four remaining subjects, improvements in FEV1 post-bronchodilator were 470, 450, 350 and $130 \mathrm{~mL}$, respectively.

\section{Impact of spirometry testing}

Between 1999 and 2003, 393 subjects were identified with postbronchodilator AFO. Of these, 235 were referred from the five practices selected for further study. Complete records could not be obtained in 18 cases; therefore complete data from 217 subjects is included in the analysis of impact of spirometry testing. Figure 2 provides a breakdown of the subjects assessed, presented as a flow diagram.

\section{Effect of spirometry upon diagnosis}

Before spirometry testing, 65 (30\%) subjects were documented as having asthma, $63(29 \%)$ were documented as having COPD, five ( $2 \%$ ) had bronchiectasis and no specific diagnosis was recorded in the notes of 84 subjects (39\%). After spirometry, 37 subjects received a new diagnosis of asthma and 91 a new diagnosis of COPD. Details of diagnoses before and after spirometry testing are shown in table 2.

\section{Demographics of the COPD patients}

After spirometry testing, 139 patients were either newly diagnosed as having COPD or confirmed to have COPD. Of these, $73(53 \%)$ were female; the mean \pm SD age was $65 \pm 11 \mathrm{yrs}$; 89 were current smokers; and the remaining 50 were exsmokers. Mean \pm SD cigarettes smoked was $42 \pm 29$ pack-yrs. Mean \pm SD FEV1 was $1.35 \pm 0.52 \mathrm{~L} \quad(55 \pm 17 \%$ pred $)$ and mean \pm SD FEV1/FVC ratio was $0.55 \pm 0.09$. A breakdown of COPD severity assessed using Global Initiative for Chronic Obstructive Lung Disease categorisation [6] is shown in table 3.

Mean "moderate" exacerbation rate (defined as an exacerbation requiring antibiotics and/or steroids but not hospitalisation [10]) was 1.47 in the year before spirometry. This rate was higher than 1-2 yrs before spirometry, when it was 0.77 $(p<0.0001)$ and also higher than 1 yr after spirometry, when it was $1.14(\mathrm{p}=0.03)$.

At the time of spirometry, 104 patients were prescribed shortacting $\beta$-agonists, 24 anticholinergics, 69 inhaled corticosteroids, 10 long-acting $\beta$-agonists and two a theophylline preparation.

In total, 125 out of these 139 subjects had undergone bronchodilator reversibility testing. Mean \pm SD FEV1 change post-bronchodilator was $0.2 \pm 0.12 \mathrm{~L}$ with an interquartile range (IQR) of $0.11-0.3 \mathrm{~L}$. Figure 3 shows a breakdown of

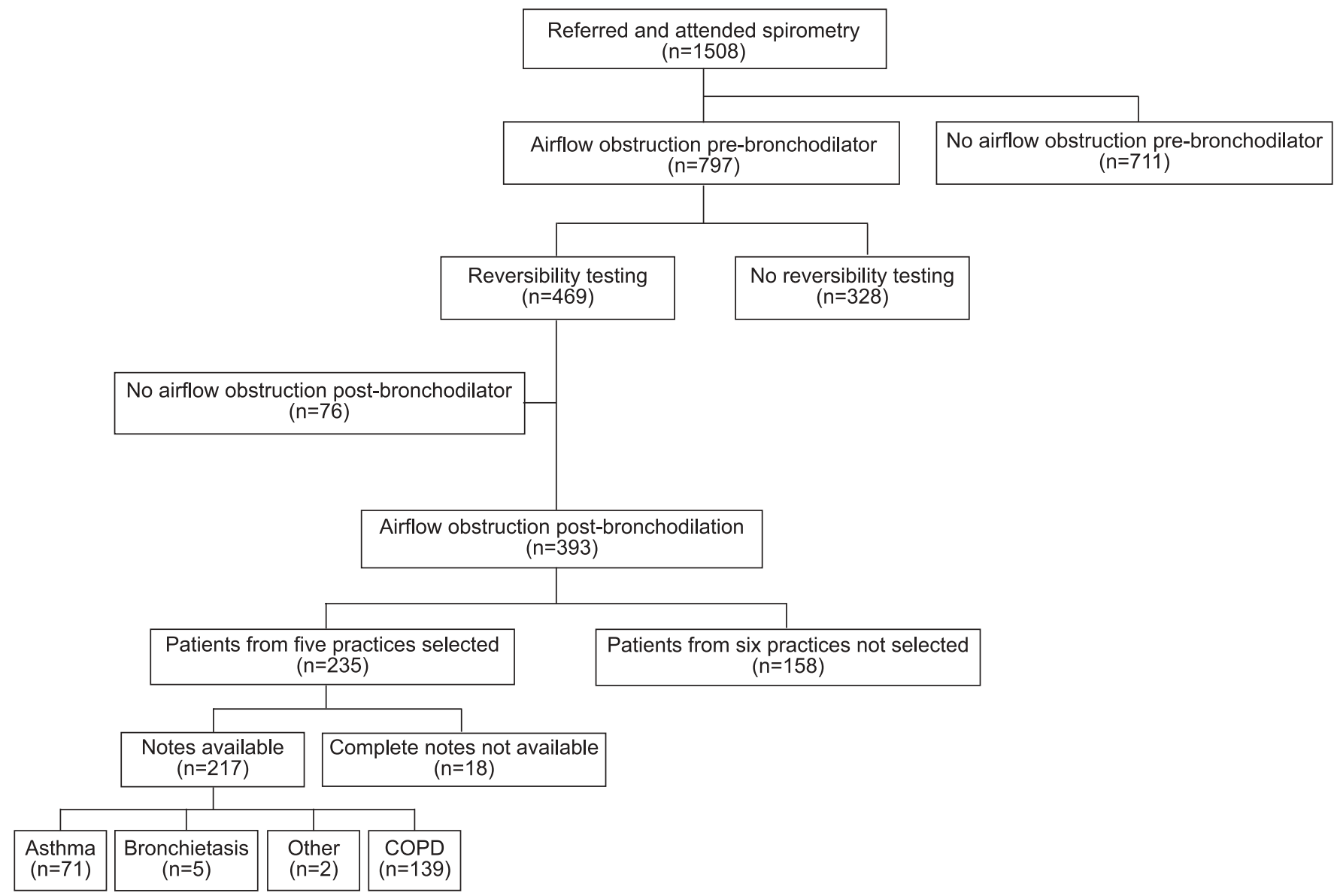

FIGURE 2. Flowchart of subject activity. COPD: chronic obstructive pulmonary disease. 


\begin{tabular}{|c|c|c|}
\hline $\begin{array}{cc}\text { TABLE } 2 & \text { Dic } \\
& \text { sp } \\
& \text { dia }\end{array}$ & $\begin{array}{l}\text { from primary-c } \\
\text { testing and th } \\
\text { as a result of } t\end{array}$ & $\begin{array}{l}\text { before } \\
\text { made to the }\end{array}$ \\
\hline $\begin{array}{l}\text { Diagnosis before } \\
\text { spirometry }\end{array}$ & $\begin{array}{l}\text { Diagnosis after } \\
\text { spirometry }\end{array}$ & Patients n \\
\hline \multirow[t]{3}{*}{ No diagnosis } & Asthma & 22 \\
\hline & COPD & 60 \\
\hline & Other & 2 \\
\hline \multirow[t]{2}{*}{ Asthma } & Asthma & 34 \\
\hline & COPD & 31 \\
\hline \multirow[t]{2}{*}{ COPD } & Asthma & 15 \\
\hline & COPD & 48 \\
\hline Bronchiectasis & Bronchiectasis & 5 \\
\hline \multirow[t]{4}{*}{ All diagnoses } & Asthma & 71 \\
\hline & COPD & 139 \\
\hline & Bronchiectasis & 5 \\
\hline & Other & 2 \\
\hline
\end{tabular}

bronchodilator responsiveness. In 88 subjects, FEV1 had been measured after a 14-day course of prednisolone; here, mean \pm SD change was $0.04 \pm 0.17 \mathrm{~L}$ with an IQR of $-0.07 \mathrm{~L}-$ $0.13 \mathrm{~L}$. A breakdown of the responses to oral corticosteroids is shown in figure 4.

\section{Effect of spirometry testing on management}

The primary- and secondary-care records of the 139 COPD patients were examined. Seven patients were either under follow-up in secondary-care chest clinics or had been seen within the previous 2 yrs and these were excluded from further analysis, leaving 132 patients. A total of 85 patients were current smokers at the time of spirometry testing. Smoking cessation advice and/or help given within 3 months of spirometry testing was documented in the primary-care notes of $65(76 \%)$ out of 85 patients.

Changes to pharmacological treatment are shown in table 4 . In total, 97 new treatments were prescribed to 64 patients. Spirometry testing led to increases in the prescription of short- and long-acting bronchodilators and inhaled corticosteroids. Prescription of short-acting $\beta$-agonists increased from 79 to $97 \%(\mathrm{p}=\mathrm{NS})$ of patients, short- and long-acting anticholinergics from 18 to $37 \%(\mathrm{p}=0.003)$ and long-acting $\beta$ agonists from 8 to $25 \%(\mathrm{p}<0.001)$. In patients with FEV1 $<50 \%$ pred, who had more than one exacerbation per year averaged over the previous $2 \mathrm{yrs}$, prescription of inhaled steroids increased from 64 to $78 \%$ ( $p=$ nonsignificant). Before spirometry testing, 46 subjects with COPD were prescribed inhaled steroids outside current recommendations (FEV1 $<50 \%$ pred and at least three exacerbations every $2 \mathrm{yrs}$ ). This number increased to 66 subjects after spirometry testing.

In total, 22 COPD patients $(17 \%)$ were referred to secondary care within 6 months of spirometry testing. Further pharmaceutical additions to currently prescribed treatment were made in nine of these patients.

\begin{tabular}{|c|c|c|}
\hline TABLE 3 & \multicolumn{2}{|c|}{$\begin{array}{l}\text { Global Initiative for Chronic Obstructive Lung } \\
\text { Disease classification of disease severity of } 139 \\
\text { subjects diagnosed with chronic obstructive } \\
\text { pulmonary disease (COPD) who underwent } \\
\text { detailed assessment of diagnosis and } \\
\text { management }\end{array}$} \\
\hline $\begin{array}{l}\text { Severity of } \\
\text { COPD }\end{array}$ & $\begin{array}{l}\text { Post-bronchodilator } \\
\text { FEV1 }\end{array}$ & $\begin{array}{c}\text { Patients } \\
\text { n }\end{array}$ \\
\hline Mild & $>80 \%$ pred & 6 \\
\hline Moderate & $50-80 \%$ pred & 78 \\
\hline Severe & $30-50 \%$ pred & 46 \\
\hline Very severe & $<30 \%$ pred & 9 \\
\hline \multicolumn{3}{|c|}{$\begin{array}{l}\text { FEV1: forced expiratory volume in one second; \% pred: percentage of predicted } \\
\text { value. The Global Initiative for Chronic Obstructive Lung Disease classification } \\
\text { taken from [6]. }\end{array}$} \\
\hline
\end{tabular}

In six out of these 22 subjects, the referral specifically requested pulmonary rehabilitation. Before spirometry testing, four subjects had completed pulmonary rehabilitation and after testing a further 10 subjects were referred for and completed the course $(p=0.018)$.

\section{DISCUSSION}

A previous study [1] has shown that primary-care spirometry testing increases the number of individuals correctly diagnosed as having COPD. The present data show for the first time that it not only improves the accuracy of diagnosis but also results in significant improvements in management, without input from secondary care. The majority of individuals who had obstructive spirometry results either received a diagnosis or had their diagnosis changed. The impact of this was not just on the COPD population, as one in six patients were newly diagnosed as having asthma. Most current smokers were provided with smoking cessation advice and significantly more patients were prescribed anticholinergics, long-acting $\beta$-agonists and inhaled corticosteroids after spirometry had been performed. A few patients were referred for pulmonary rehabilitation. Based on evidence from clinical trials [11-17], the potential sequelae of this would be improved lung function, better exercise capacity and improved healthrelated quality of life. A reduction in PCP-treated exacerbations in the year following spirometry was also found. However, it is not possible to know whether the decrease in exacerbation rate after testing is consistent with the effect of changes in management; whether the higher exacerbation rate in the year before testing influenced referral for spirometry testing; whether this represents a "regression to the mean" effect; or whether, more likely, a combination of all three factors is in play.

Primary-care spirometry is often performed in the practice by primary-care staff, who have sometimes had little training either in performing spirometry or interpreting the results. This raises potential quality-control issues concerning the calibration of equipment, the performance of the tests to an accepted standard and the interpretation and classification of results. The model of service used in the present study 


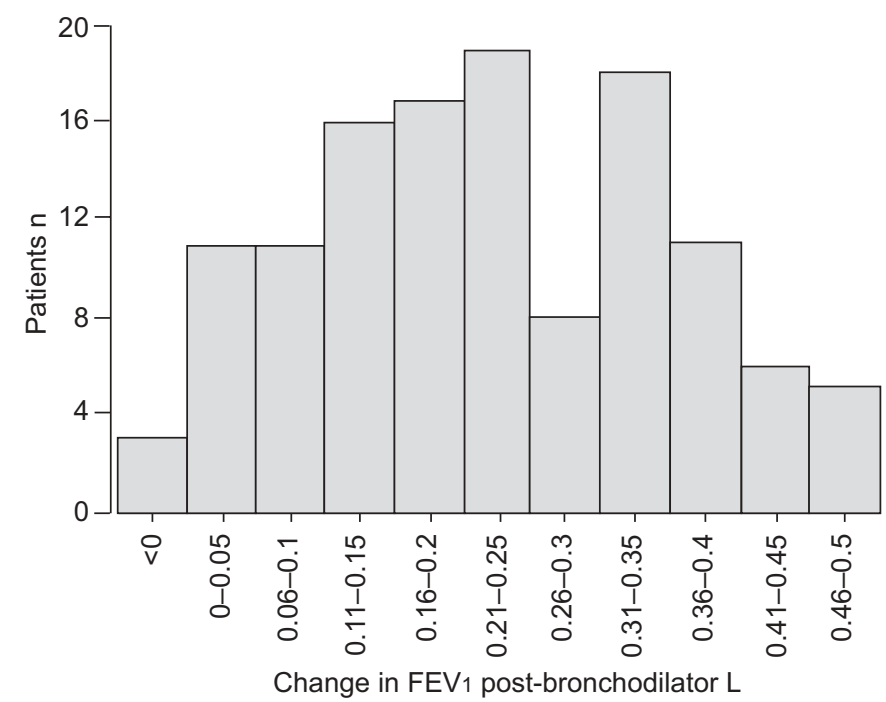

FIGURE 3. Change in forced expiratory volume in one second (FEV 1 ) postbronchodilator in 125 subjects diagnosed with chronic obstructive pulmonary disease.

involves an experienced physiologist obtaining accurate spirometry results which meet accepted standards for testing and are then interpreted for the referrer. The present authors believe that this "model" of testing is an alternative to inpractice testing that will in many cases produce more accurate results and hence subsequent diagnosis.

Although significant improvements in management occurred, the numbers suggest there is still significant undertreatment. Clearly it is impossible to establish exactly how symptomatic an individual patient is and in any case individuals with mild AFO and few symptoms would not be considered for pharmacological or exercise therapy. However, if these subjects were current smokers they would receive smoking cessation input. Moreover, a considerable proportion of patients with severe or very severe COPD, and the majority of patients with moderate COPD, were taking neither anticholinergics nor long-acting $\beta$-agonists. Only a very small number of symptomatic patients likely to benefit were referred for pulmonary rehabilitation. Addressing this gap in treatment will require both education and development of care pathways in primary care and it is hoped that the instigation of COPD registers in primary care will aid this process. The issue of provision of open access to pulmonary rehabilitation should also be reconsidered.

Despite general undertreatment, there appears to be overprescription of inhaled corticosteroids compared with current recommendations for their use [18]. In some subjects, inhaled corticosteroids may be prescribed for persistent breathlessness despite maximum bronchodilator therapy [7], although, considering the general level of undertreatment, this is unlikely to be the case for many patients. Even after spirometry testing, inhaled corticosteroids were added to the treatment regimen of 25 patients, although there was only a clear indication for their addition in five cases. This again suggests a need for improvement in primary-care education. Despite this, the present authors have been reluctant to suggest withdrawal of

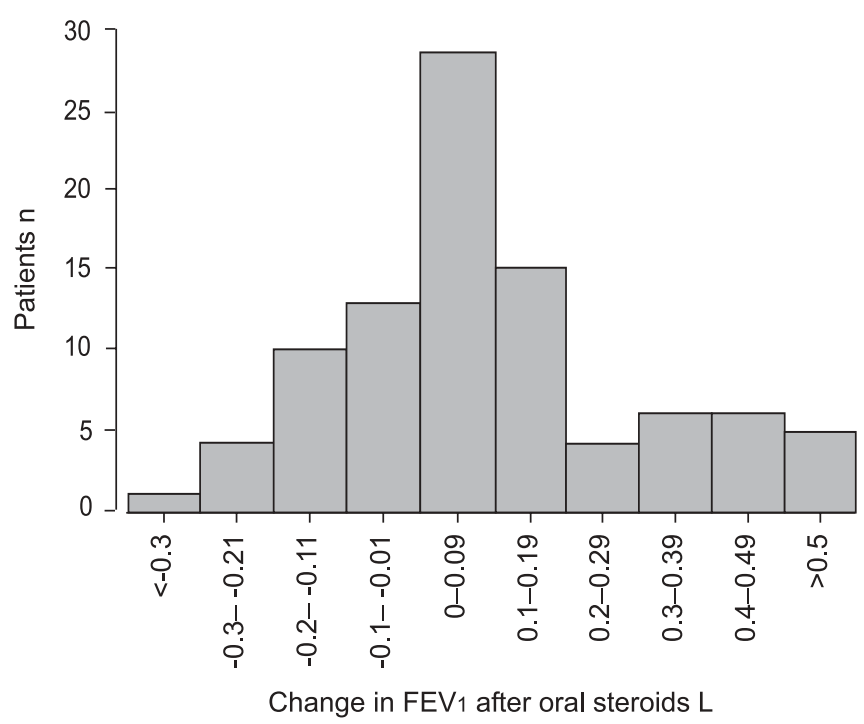

FIGURE 4. Change in forced expiratory volume in one second (FEV1) after oral steroid in 88 subjects diagnosed with chronic obstructive pulmonary disease.

inhaled steroids in light of recent publications highlighting clinical deterioration after withdrawal [19-21].

The current study also clearly demonstrates the value, in primary care, of bronchodilator reversibility testing in subjects with obstructive spirometry results pre-bronchodilator. Nearly one in five patients changed from having AFO to not having AFO once bronchodilators had been administered. The potential consequences of misdiagnosis include worry for the patient, provision of incorrect information, loss of trust if an incorrect diagnosis were later changed, inappropriate treatment and potential side-effects from that treatment as well as potential effects on the ability to obtain travel, employment and life insurance. The present data suggest that it is highly unlikely that airflow obstruction will return to normal if the pre-bronchodilator FEV1/FVC ratio is $<0.5$. However, it is important that bronchodilator reversibility testing be performed where the ratio is $0.5-0.69$. Reversibility testing is included in the current GMS contract [3] but is not recommended in the recent UK National Institute for Health and Clinical Excellence guidelines [7]. While it is clear that reversibility testing should not be used to plan treatment for COPD [22], the present data suggest that omission of reversibility testing is likely to produce diagnostic errors. It has been the current authors' practice for $>10$ yrs to use highdose nebulised bronchodilators to perform reversibility testing. No problems with this policy have been encountered, although terbutaline would be substituted for salbutamol in the event of a declared intolerance for salbutamol. However, the present authors accept that many clinicians may feel uncomfortable using these doses and suggest that $200-400 \mu \mathrm{g}$ salbutamol inhaled using a large-volume spacer is an acceptable alternative.

It has recently been clearly established using data from the Inhaled Steroids in Obstructive Lung Disease in Europe trial that response to steroids in COPD patients predicts neither response to treatment nor subsequent decline in lung function [23]. Measurement of response to oral prednisolone was used 


\begin{tabular}{|c|c|c|c|c|c|}
\hline \multirow{2}{*}{$\begin{array}{l}\text { TABLE } 4 \\
\text { Treatment }\end{array}$} & \multicolumn{5}{|c|}{$\begin{array}{l}\text { Changes to pharmacological therapy in } 132 \text { chronic obstructive pulmonary disease patients within } 3 \text { months of } \\
\text { spirometry testing }\end{array}$} \\
\hline & & Patients & $\begin{array}{l}\text { Patients prescribed treatment } \\
\text { before spirometry }\end{array}$ & $\begin{array}{l}\text { Patients prescribed treatment after } \\
\text { spirometry }\end{array}$ & $\mathrm{p}$-value \\
\hline \multicolumn{2}{|c|}{ Short-acting $\beta$-agonists ${ }^{\#}$} & 132 & $104(79)$ & $128(97)$ & NS \\
\hline \multicolumn{2}{|c|}{ Anticholinergics" } & 132 & $24(18)$ & $49(37)$ & 0.003 \\
\hline \multicolumn{2}{|c|}{ Inhaled corticosteroids ${ }^{\S}$} & 132 & $69(52)$ & $94(71)$ & 0.05 \\
\hline \multicolumn{2}{|c|}{$\begin{array}{l}\text { Inhaled corticosteroids in patients } \\
\text { with } \mathrm{FEV} 1<\mathbf{5 0} \% \text { pred and }>1 \\
\text { exacerbation } \cdot \mathrm{yr}^{-1}\end{array}$} & 36 & $23(64)$ & $28(78)$ & NS \\
\hline
\end{tabular}

Data are presented as $\mathrm{n}$ or $\mathrm{n}(\%)$ unless otherwise stated. FEV1: forced expiratory volume in one second; \% pred: percentage of predicted value; NS: not significant. \# salbutamol and terbutaline; " : ipratropium, oxitropium and tiotropium; ${ }^{+}$: salmeterol and formoterol; ${ }^{\text {s: }}$ beclometasone, budesonide and fluticasone.

as a diagnostic tool in the present study (though an alternative would be to prescribe either an inhaled corticosteroid or a combined corticosteroid/long-acting $\beta$-agonist inhaler for 2 6 weeks before repeating spirometry), and where FEV1 improved by $>500 \mathrm{~mL}$ a likely diagnosis of asthma was mooted. The present authors found that this rarely provided useful additional information once bronchodilator reversibility testing had been performed. In only four out of 371 cases was there a dramatic response to corticosteroids where there was a $<500 \mathrm{~mL}$ response to bronchodilators, and in two of these four patients bronchodilator response was $450-500 \mathrm{~mL}$. The present authors ceased offering the test in 2004 unless there was a high clinical suspicion of asthma as it was felt that, in general, the potential risks of the steroid course outweighed the likely benefit from any information gained. However, it must be acknowledged that there may be very occasional patients in whom asthma is missed by simple spirometry and bronchodilator reversibility testing. Ultimately, the supervising clinician will need to decide whether this small increase in asthma diagnosis merits the potential risks from the medication and increased cost of medication and further spirometry testing.

The study is a retrospective review and because of this it faces methodological challenges. Any retrospective review is clearly limited by the information recorded, but all relevant documentation for nearly $95 \%$ of patients was obtained in the present study, and the few patients for whom this was not possible were excluded from analysis. Although the notes of every individual with post-bronchodilator obstructive spirometry were not reviewed, by randomly selecting five practices, $>50 \%$ of cases (the original target) were reviewed and the present authors believe a true representative sample of patients was analysed. Using a fixed threshold of FEV1/FVC $<0.7$ for the diagnosis of AFO, as suggested in current guidelines, leads to a proportion of older patients being diagnosed as having mild COPD when in fact they may have normal lung function for their age. The FEV1/FVC ratio falls with age and in some cases the "mild airflow obstruction" seen is in fact physiological and normal. In light of this, it is important to ensure that treatment is reserved for symptomatic individuals and not simply based on spirometry results. It is possible that discussion about smoking cessation was not always recorded, although computerisation and GMS contractual requirements make this unlikely. Computerised prescribing ensures that data on medication use is reasonably accurate and review of secondary care notes provided additional information. When addressing prescription of pharmaceutical agents, the problems of cessation due to side-effects or lack of efficacy were avoided by recording a medication as "prescribed" when three monthly prescriptions had been collected. Hence, where management is assessed post-spirometry, the results probably represent the minimum impact. It is hoped that, despite the methodological problems inherent in the study design, the trial provides data that can be used to generate hypotheses and ultimately lead to the design and funding of a prospective randomised study addressing the impact of primary-care spirometry.

Spirometry should not be used in isolation to make a diagnosis. Using information recorded in primary and secondary care notes, the present authors have attempted to confirm or refute diagnoses obtained from spirometry testing, but it should be recognised that individuals with asthma and COPD show considerable overlap in their responses to bronchodilators and corticosteroids. In the current study, a post-medication improvement in FEV1 of $500 \mathrm{~mL}$ was regarded as likely to suggest asthma, but it is recognised that some asthmatic individuals smoke heavily and will have emphysema and individuals with severe asthma and fixed AFO often do not "reverse". In general it is clear from the primary- and secondary-care notes which patients have severe asthma and in fact very few of these patients underwent spirometry, since the diagnosis was already established.

In conclusion, the results of the present study have shown that primary-care spirometry has a considerable impact on both diagnosis and subsequent management, including utilisation of treatments that have been shown to have an important impact on clinical end-points. Reversibility testing, for diagnostic purposes, is recommended in anyone with modest degrees of airflow obstruction.

\section{ACKNOWLEDGEMENTS}

The authors would like to thank the primary-care physicians, managers and members of staff at each of the practices involved for their help with this study. 


\section{REFERENCES}

1 Griffiths C, Feder G, Wedzicha J, Foster G, Livingstone A, Marlowe GS. Feasibility of spirometry and reversibility testing for the identification of patients with chronic obstructive pulmonary disease on asthma registers in general practice. Respir Med 1999; 93: 903-908.

2 Sauro A, Scalzitti F, Buono N, et al. Spirometry is really useful and feasible in the GP's daily practice but guidelines alone are not. Eur J Gen Pract 2005; 11: 29-31.

3 The National Health Service (General Medical Services Contracts) Regulations 2004. London, The Stationery Office Limited, 2004.

4 Bolton CE, Ionescu AA, Edwards PH, Faulkner TA, Edwards SM, Shale DJ. Attaining a correct diagnosis of COPD in general practice. Respir Med 2005; 99: 493-500.

5 Walters JA, Hansen E, Mudge P, Johns DP, Walters EH, Wood-Baker R. Barriers to the use of spirometry in general practice. Aust Fam Physician 2005; 34: 201-203.

6 Global Initiative for Chronic Lung Disease. GOLD Workshop Report, 2005 update. http://www.goldcopd. com/download.asp?intId=231. Date last updated: September 2005. Date last accessed: August 17, 2005.

7 National Collaborating Centre for Chronic Conditions, Chronic obstructive pulmonary disease. National clinical guideline on management of chronic obstructive pulmonary disease in adults in primary and secondary care. Thorax 2004; 59: Suppl. 1, 1-232.

8 Quanjer PH, Tammeling GJ, Cotes JE, Pedersen OF, Peslin R, Yernault JC. Lung volumes and forced ventilatory flows. Report Working Party Standardization of Lung Function Tests, European Community for Steel and Coal. Official Statement of the European Respiratory Society. Eur Respir J 1993; 6: Suppl. 16, 5-40.

9 Quanjer PH. Standardised lung function testing. Bull Eur Physiopathol Respir 1983; 19: 66-92.

10 Rodriguez-Roisin R. Toward a consensus definition for COPD exacerbations. Chest 2000; 117: Suppl. 2, 398S-401S.

11 Vincken W, van Noord JA, Greefhorst AP, et al. Improved health outcomes in patients with COPD during $1 \mathrm{yr}$ 's treatment with tiotropium. Eur Respir J 2002; 19: 209-216.

12 Casaburi R, Mahler DA, Jones PW, et al. A long-term evaluation of once-daily inhaled tiotropium in chronic obstructive pulmonary disease. Eur Respir J 2002; 19: 217-224.

13 The COMBIVENT Inhalation Solution Study Group. Routine nebulised ipratropium and albuterol together are better than either alone in COPD. Chest 1997; 112: 1514-1521.

14 Calverley PM, Boonsawat W, Cseke Z, Zhong N, Peterson S, Olsson H. Maintenance therapy with budesonide and formoterol in chronic obstructive pulmonary disease. Eur Respir J 2003; 22: 912-919.

15 Calverley P, Pauwels R, Vestbo J, et al. Combined salmeterol and fluticasone in the treatment of chronic obstructive pulmonary disease: a randomised controlled trial. Lancet 2003; 361: 449-456.

16 Szafranski W, Cukier A, Ramirez A, et al. Efficacy and safety of budesonide/formoterol in the management of chronic obstructive pulmonary disease. Eur Respir J 2003; 21: 74-81.

17 Griffiths TL, Burr ML, Campbell IA, et al. Results at 1 year of outpatient multidisciplinary pulmonary rehabilitation: a randomised controlled trial. Lancet 2000; 355: 362-368.

18 Burge PS, Calverley PM, Jones PW, Spencer S, Anderson JA, Maslen TK. Randomised, double blind, placebo-controlled study of fluticasone propionate in patients with moderate to severe chronic obstructive pulmonary disease: the ISOLDE trial. BMJ 2000; 320: 1297-1303.

19 van der Valk P, Monninkhof E, van der Palen J, Zielhuis G, van Herwaarden C. Effect of discontinuation of inhaled corticosteroids in patients with chronic obstructive pulmonary disease: the COPE study. Am J Respir Crit Care Med 2002; 166: 1358-1363.

20 Wouters EF, Postma DS, Fokkens B, et al. Withdrawal of fluticasone propionate from combined salmeterol/fluticasone treatment in patients with COPD causes immediate and sustained disease deterioration: a randomised controlled trial. Thorax 2005; 60: 480-487.

21 van der Palen J, Monninkhof E, van der Valk P, Sullivan SD, Veenstra DL. Cost effectiveness of inhaled steroid withdrawal in outpatients with chronic obstructive pulmonary disease. Thorax 2006; 61: 29-33.

22 Calverley PM, Burge PS, Spencer S, Anderson JA, Jones PW. Bronchodilator reversibility testing in chronic obstructive pulmonary disease. Thorax 2003; 58: 659-664.

23 Burge PS, Calverley PM, Jones PW, Spencer S, Anderson JA. Prednisolone response in patients with chronic obstructive pulmonary disease: results from the ISOLDE study. Thorax 2003; 58: 654-658. 